\title{
Characterisation of Burkholderia cepacia from cystic fibrosis patients living in Wales by PCR ribotyping
}

\author{
H. C. RYLEY, L. MILLAR-JONES*, A. PAULL and J. WEEKS \\ Department of Medical Microbiology and Public Health Laboratory and Department of Child Health, University of \\ Wales College of Medicine, Heath Park, Cardiff CF 4 4XN
}

\begin{abstract}
Summary. Polymerase chain reaction (PCR) ribotyping detects differences in the intergenic spacer region between the $16 \mathrm{~S}$ and $23 \mathrm{~S}$ rRNA genes. This method was applied to Burkholderia cepacia isolates from 16 Welsh cystic fibrosis (CF) patients attending three different clinics. Amplification of the intergenic spacer followed by an additional digestion step with $T a q$ I restriction endonuclease identified seven distinct electrophoretic patterns among the patient isolates. Each of the seven patterns was distinct from that of the so called "epidemic strain" commonly isolated from patients attending clinics elsewhere in the UK. Two environmental isolates from the hospital clinics and four NCTC reference strains gave different patterns. The simplicity of the method lends itself to use in a general microbiological laboratory.
\end{abstract}

\section{Introduction}

Burkholderia cepacia has emerged recently as an important opportunist respiratory pathogen of cystic fibrosis (CF) patients whose acquisition of B. cepacia is associated with a poor prognosis. ${ }^{1,2}$ In Wales, the incidence of $B$. cepacia isolates from $\mathrm{CF}$ patients is generally lower than that reported in other UK regions ${ }^{3,4}$ but it has risen in recent years. Consequently, clinical management of the infection has become an increasing priority and an understanding of the epidemiology within this patient population is essential. A number of typing methods-including bacteriocin typing, ribotyping and pulsed field gel electrophoresis (PFGE) - have been applied to $B$. cepacia ${ }^{5-8}$ but most methods are unsuitable for the routine clinical laboratory because of the complexity of the methods or the need to obtain substantial control and indicator organisms.

In 1992. Kostman et al. ${ }^{9}$ showed that epidemiologically unrelated isolates of $B$. cepacia could be differentiated by the amplification patterns of the intergenic spacer regions between the 16S rRNA and 23S rRNA genes. Most bacteria have multiple copies of the ribosomal RNA operon and the length and sequence of the $16 \mathrm{~S}-23 \mathrm{~S}$ intergenic spacer regions within the operons can differ both between operons on the same genome and between operons within a bacterial species. Therefore, amplification of these

Received 23 Feb. 1995; revised version accepted 5 May 1995. spacer regions yields multiple products which, after electrophoretic separation, yields patterns that may be strain specific.

This method was evaluated for B. cepacia isolates from a Welsh CF patient population and the findings are reported here, together with methodological modifications to improve speed and specificity.

\section{Methods and materials}

\section{Patients and bacterial isolates}

Since 1989 , B. cepacia has been isolated from nine patients attending the paediatric $\mathrm{CF}$ clinic at the University Hospital of Wales, Cardiff, five patients attending the CF adult clinic at Llandough Hospital, Cardiff and two further patients attending clinics in South Wales (Swansea) and West Wales (Carmarthen). One of these patients (patient $R$, see the table) had shared care with the adult CF clinic in Cardiff and attended that clinic on a bi-annual basis. The organism was first isolated from a sputum specimen collected at the Cardiff adult clinic. The two CF clinics in Cardiff are sited in hospitals on opposite sides of the city and there is no known patient contact between the attendees of each clinic.

B. cepacia was isolated from sputum specimens by culture on Pseudomonas cepacia Selective Medium containing ticarcillin and polymyxin B (Mast Diagnostic Ltd, Merseyside) and identified with the API $20 \mathrm{NE}$ test system (bioMérieux). Environmental isolates were obtained from swabs taken from sinks in 
Table. Comparison of the modified PCR ribotype with bacteriocin and PFGE typing results

\begin{tabular}{llllll}
\hline Patient & \multicolumn{1}{c}{ Clinic } & $\begin{array}{c}\text { PCR } \\
\text { ribotype }\end{array}$ & $\begin{array}{c}\text { TaqI PCR } \\
\text { ribotype }\end{array}$ & $\begin{array}{c}\text { Bacteriocin } \\
\text { type }\end{array}$ & $\begin{array}{c}\text { PFGE } \\
\text { type }\end{array}$ \\
\hline A & Cardiff paediatric CF clinic & I & P1 & S13/PO mel & 1 \\
B & Cardiff paediatric CF clinic & I & P1 & S13/PO mel & 1 \\
C & Cardiff paediatric CF clinic & I & P1 & S13/PO mel & 1 \\
D & Cardiff paediatric CF clinic & I & P1 & S13/PO mel & 1 \\
E & Cardiff paediatric CF clinic & I & P1 & S13/PO mel & 1 \\
F & Cardiff paediatric CF clinic & I & P1 & ND & 1 \\
G & Cardiff paediatric CF clinic & II & P2 & S22/PO & 3 \\
H & Cardiff paediatric CF clinic & III & P3 & ND & 4 \\
J & Cardiff paediatric CF clinic & I & P1 & S13/PO mel & 1 \\
K & Swansea paediatric clinic & IV & P4 & ND & 5 \\
L & Cardiff adult CF clinic & V & A1 & S22/PO & 2 \\
M & Cardiff adult CF clinic & V & A1 & S22/PO & 2 \\
N & Cardiff adult CF clinic & II & A2 & ND & ND \\
O & Cardiff adult CF clinic & V & A1 & ND & 2 \\
P & Cardiff adult CF clinic & V & A1 & S22/PO & 2 \\
R & Carmarthen with shared care & VI & A3 & ND & 6 \\
& with Cardiff adult CF clinic & & & & \\
\hline
\end{tabular}

ND, not determined.

adjacent rooms in the paediatric $\mathrm{CF}$ clinic, a sink in the adult $\mathrm{CF}$ clinic and from a bacteriological blood culture bottle believed to have been contaminated with B. cepacia at point of manufacture and prior to use. In addition, NCTC strains 10661, 10734, 10743 and 10744 were obtained from the National Collection of Type Cultures, 61 Colindale Avenue, London. Also included was a clinical isolate representing the "epidemic strain" described by Govan et al. ${ }^{5}$ as the predominant $B$. cepacia strain in patients attending other CF clinics in the UK. All isolates were stored at $-70^{\circ} \mathrm{C}$ in Microbank vials (Pro-Lab Diagnostics, Canada) and subcultured on to the B. cepacia selective medium for further study.

\section{Extraction of B. cepacia DNA}

Genomic DNA was extracted by the Chelex 100 resin method. ${ }^{10}$ Briefly, one 5- $\mu$ l loopful of organisms was harvested from a culture plate and suspended in phosphate-buffered saline, $\mathrm{pH} 7 \cdot 3$, in a $1.5-\mathrm{ml}$ Eppendorf tube, centrifuged, and the pellet was resuspended in $100 \mu \mathrm{l}$ of water; $100 \mu \mathrm{l}$ of a suspension of Chelex 100 (BioRad Laboratories Ltd) $10 \% \mathrm{w} / \mathrm{v}$ in distilled water was added. The mixture was vortex mixed for $15 \mathrm{~s}$, heated in a boiling water bath for $5 \mathrm{~min}$, cooled and then centrifuged at $11600 \mathrm{~g}$ for $2 \mathrm{~min}$. The supernate was transferred to a fresh tube and the DNA content was estimated with the aid of a Pharmacia GeneQuant RNA/DNA Calculator (Pharmacia LKB Biochrom Ltd).

During the development of this study, two other methods of DNA template preparation were tried. These methods were the phenol-chloroform extraction method as described by Kostman et al. ${ }^{9}$ and a celiteguanidinium thiocyanate absorption method described by Boom et al. ${ }^{11}$

\section{PCR amplification of $16 S-23 S \mathrm{rRNA}$ intergenic spacer regions}

Amplifications were performed in a total volume of $100 \mu$ containing $1.25 \mathrm{U}$ of GeneAmp Taq polymerase (Perkin-Elmer Cetus), a 1 in 10 dilution of the buffer provided with the enzyme, a final magnesium chloride concentration of $1.5 \mathrm{mM}, 200 \mu \mathrm{M}$ of each deoxynucleoside triphosphate ( $100 \mathrm{~mm}$ stock solutions from Pharmacia Biotech), 100 pmols each of the primers (1:5'-TTGTACACACCGCCCGTCA-3' and 2:5'GGTACCTTAGATGTTTCAGTTC- $\left.3^{\prime}\right)^{9}$ and $c .1 \mu \mathrm{g}$ of DNA template. Amplification conditions were as described by Kostman et al. ${ }^{9}$ and the cycles were performed in a Grant Autogene II Programmable Cycling Water Bath (Grant Instruments (Cambridge) Ltd, Cambridge). Other sources of Taq polymerase were used, including Taq polymerase (Promega) and Dynazyme (Flowgen Instrument Ltd,) with similar results.

\section{Purification of PCR products}

To optimise the conditions for the subsequent restriction endonuclease digestion step, it was necessary to both concentrate and transfer the PCR amplification products into water and this was achieved by a modified silica extraction method. ${ }^{11}$ A suspension of silica particles (Silicon Dioxide; Sigma) $50 \%$ w/v in 10 mM HCl was prepared after particles had been washed and fractionated. ${ }^{11}$ The $100 \mu \mathrm{l}$ of PCR amplified solution were placed in a $1.5-\mathrm{ml}$ centrifuge tube and $900 \mu \mathrm{l}$ of guanidinium thiocyanate lysis buffer $(4.6 \mathrm{M}$ guanidinium thiocyanate, $20 \mathrm{~mm}$ EDTA and Triton $\mathrm{X} 1001.2 \%$ in $50 \mathrm{~mm}$ TrisCl buffer, $\mathrm{pH} 6.4$ ) were added, followed by $10 \mu \mathrm{l}$ of silica suspension. After a brief vortex mix, the mixture was allowed to stand for $10 \mathrm{~min}$, mixed, and centrifuged at $11600 \mathrm{~g}$ for $2 \mathrm{~min}$ 
and the supernate was carefully discarded. The pellet was resuspended in $1 \mathrm{ml}$ of guanidinium thiocyanate washing buffer $(5.6 \mathrm{M}$ guanidinium thiocyanate in $50 \mathrm{~mm}$ TrisCl, pH 6.4) centrifuged at $11600 \mathrm{~g}$ for $2 \mathrm{~min}$, washed twice with ethanol $70 \%$ and any residual ethanol wash was removed. The silica-DNA pellet was resuspended in $30 \mu \mathrm{l}$ of distilled water, heated at $56^{\circ} \mathrm{C}$ for $10 \mathrm{~min}$, centrifuged at $11600 \mathrm{~g}$ for 2 min and the supernate containing extracted DNA was transferred to a fresh tube. The pellet was resuspended in $20 \mu$ of distilled water, mixed, centrifuged as before and the resulting supernate was combined with the other. The DNA content of the combined extract was estimated by the GeneQuant DNA/RNA calculator. Three- $\mu$ amounts were separated by electrophoresis in agarose gel $1.5 \%$ in $100 \mathrm{~mm}$ Tris, $83 \mathrm{~mm}$ boric acid, $1 \mathrm{~mm}$ sodium EDTA electrophoresis buffer (TBE buffer) and stained with ethidium bromide $0.05 \%$.

\section{Restriction endonuclease digestion of PCR products}

Amplification products were digested with each of eight restriction endonucleases to determine which gave the best discrimination between isolates. Seven endonucleases had a four-base recognition site ( $A l u \mathrm{I}$, HaeIII, Hinfl, HpaII, RsaI, Sau3A and TaqI) and one had a five-base recognition site ( $D d e I)$. All enzymes were obtained from Appligene and used with a 10-fold dilution of appropriate buffer supplied by the manufacturer. In each case, $400 \mathrm{ng}$ of PCR products were digested for $2 \mathrm{~h}$ with 5 units of enzyme at $37^{\circ} \mathrm{C}$ with the exception of TaqI, in which case digestion was performed at $65^{\circ} \mathrm{C}$. The restriction fragments were analysed by electrophoresis in an agarose gel (Metaphor Agarose; FMC Bioproducts) $2.5 \%$ in the TBE electrophoresis buffer, stained with ethidium bromide $0.05 \%$ and photographed with UV transillumination.

\section{Alternative methods of typing $B$. cepacia}

The isolates in this study were also typed independently by bacteriocin production and sensitivity ${ }^{5}$ (Professor J. R. W. Govan, University of Edinburgh) and by PFGE under the conditions described by Smith et al. ${ }^{4}$ (Dr T. L. Pitt, Central Public Health Laboratory, 61 Colindale Avenue, London).

\section{Results and discussion}

In their original method, Kostman et al ${ }^{9}$ extracted DNA from $B$. cepacia grown in liquid medium overnight by classical phenol-chloroform extraction procedures. The extraction method used in the present study, based on the use of a suspension of Chelex 100 and heating in a boiling water bath for $5 \mathrm{~min}$, involves no potentially harmful chemicals and can be performed with small amounts of bacteria (two-to-five colonies) taken from solid media where contaminating organisms can be detected readily. In this study, DNA extracted by phenol-chloroform, celite-guanidinium thiocyanate absorption or Chelex 100 method gave identical results when used in the subsequent PCR but the latter method was by far the most rapid.

From the typing of the Welsh $B$. cepacia isolates done by other laboratories, it was known that there were at least six strain types present in the isolates from the $16 \mathrm{CF}$ patients (table). However, in contrast with the original report of Kostman et al..$^{9}$ and a subsequent report from Dasen et al., ${ }^{12}$ little or no differences were found between the PCR ribotyping patterns from the $B$. cepacia strains analysed here. It was not possible to differentiate the types subsequently identified as P3, A2 and the "epidemic strain" (fig. 1) with this method. Increasing the time of separation or concentration of agarose, or both, gave no improvement. The original method is based on the detection of differences in molecular size of the $16 \mathrm{~S}-23 \mathrm{~S}$ intergenic spacer regions. However, restriction endonuclease digestion of the amplification products with subsequent electrophoretic analysis could detect possible nucleotide base sequence differences and this approach was investigated in the present study. Of the eight restriction endonucleases used to digest the $16 \mathrm{~S}-23 \mathrm{~S}$ intergenic spacer amplification products from the 16 isolates, three, TaqI, RsaI and HpaII, gave seven different electrophoretic patterns. Pattern differentiation was based on the number of bands and the relative position and intensity of each band within the electrophoretic pattern. TaqI digestion produced the largest electrophoretic pattern variation between the seven Welsh strain types and was, therefore, considered the most suitable for epidemiological studies. Three electrophoretic patterns were detected with TaqI digestion of PCR products from the nine isolates from the Cardiff paediatric clinic (types $\mathrm{P} 1, \mathrm{P} 2, \mathrm{P} 3$ ) and the isolate from the paediatric patient attending the Swansea clinic gave a different electrophoretic pattern (type P4) (fig. 2). Three further distinct electrophoretic patterns (types A1, A2, A3) were obtained from isolates from the patients attending the Cardiff adult clinic. Each of these electrophoretic patterns was clearly distinct from that obtained with the "epidemic strain" of Govan et $a .^{5}$ (fig. 2). Within the Cardiff paediatric clinic, seven patients carried the P1 type, and types P2 and P3 were isolated from single patients. Within the Cardiff adult clinic, four patients carried the type A1 strain and types A2 and A3 were isolated from single patients. Because epidemiologically unrelated isolates from the three clinics gave different patterns, the sharing of a similar type such as P1, by patients attending the same clinic is probably indicative of cross-infection between patients. The opportunity for such cross-infection, including concurrent admission to the same ward, has been shown for the paediatric patients carrying the P1 type $^{13}$ and adult patients carrying Al type (MillarJones, unpublished data). Patients carrying an unique type had probably acquired the organism from outside the clinic.

Of the four environmental isolates examined, two from sinks in adjacent rooms in the paediatric out- 


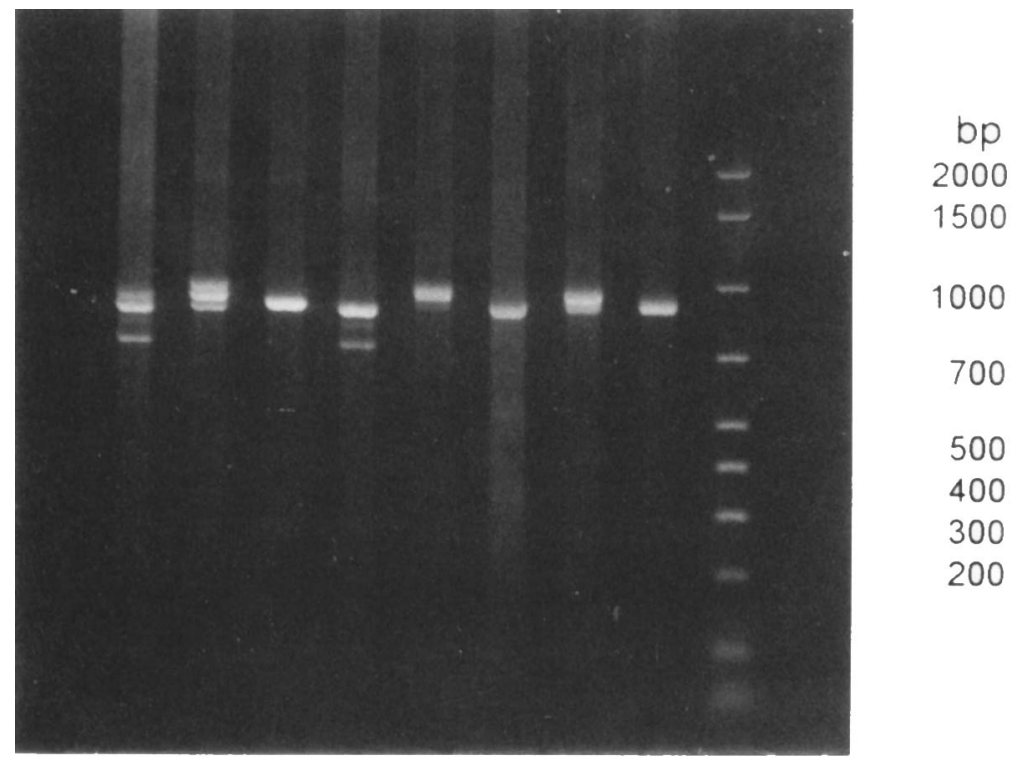

\section{P1 P2 P3 P4 A1 A2 A3 ES M}

Fig. 1. Amplification products of the 16S-23S rRNA intergenic spacer region of the four B. cepacia isolate types from paediatric CF patients (P1-4), three B. cepacia isolate types from the adult CF patients (A1-3) and the epidemic strain (ES). M, BioRad ampliSize DNA markers.

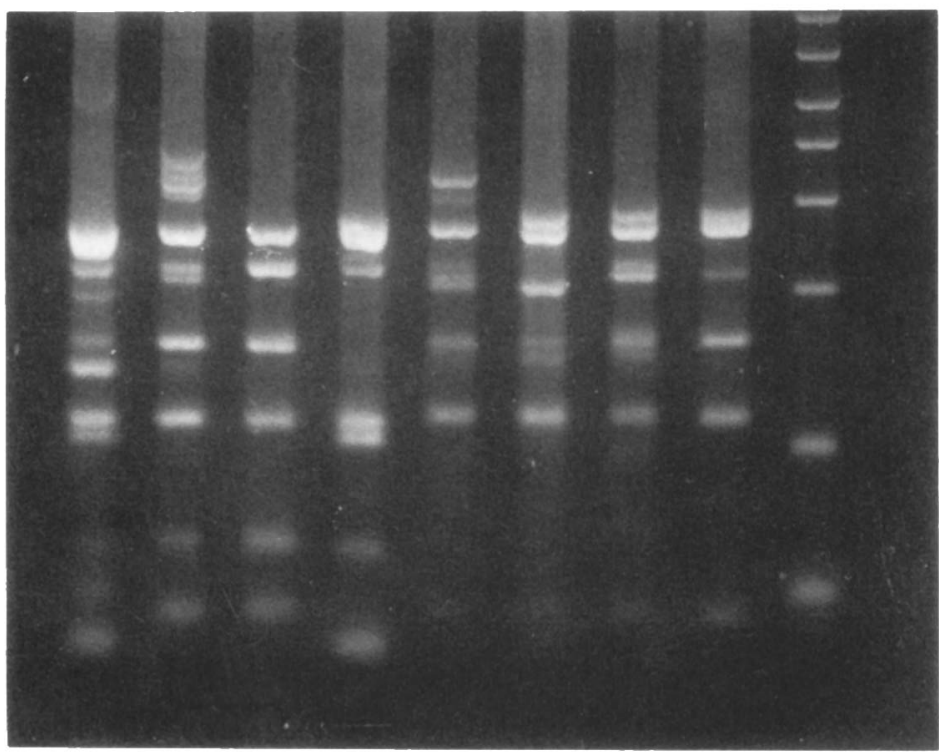

\section{P1 P2 P3 P4 A1 A2 A3 ES $M$}

Fig. 2. TaqI digests of the amplification products of the 16S-23S rRNA intergenic spacer region from the four $B$. cepacia isolate types from paediatric CF patients (P1-4), three B. cepacia isolate types from the adult CF patients (A1-3) and the epidemic strain (ES). M, BioRad ampliSize DNA markers.

patients clinic (type E1) and one from a sink in the adult out-patients (type E1') were indistinguishable (fig. 3). A fourth organism isolated from a contaminated bacteriological blood culture bottle (type E2) was a different type from the others. The non-clinical isolates were clearly differentiated from the clinical isolates and the four reference strains (fig. 3).

The reproducibility of the method was examined with DNA extracts from five isolates with different pattern types. In all cases, the profiles obtained after TaqI digestion of the PCR products from different target preparations of the same isolate were very similar. However, there was variation in the concentration, although not in the size, of the initial PCR products, despite apparently identical processing. This variation in concentration appeared to be related to the quality of the extracted DNA template. The most consistent results were obtained when fresh cultures 


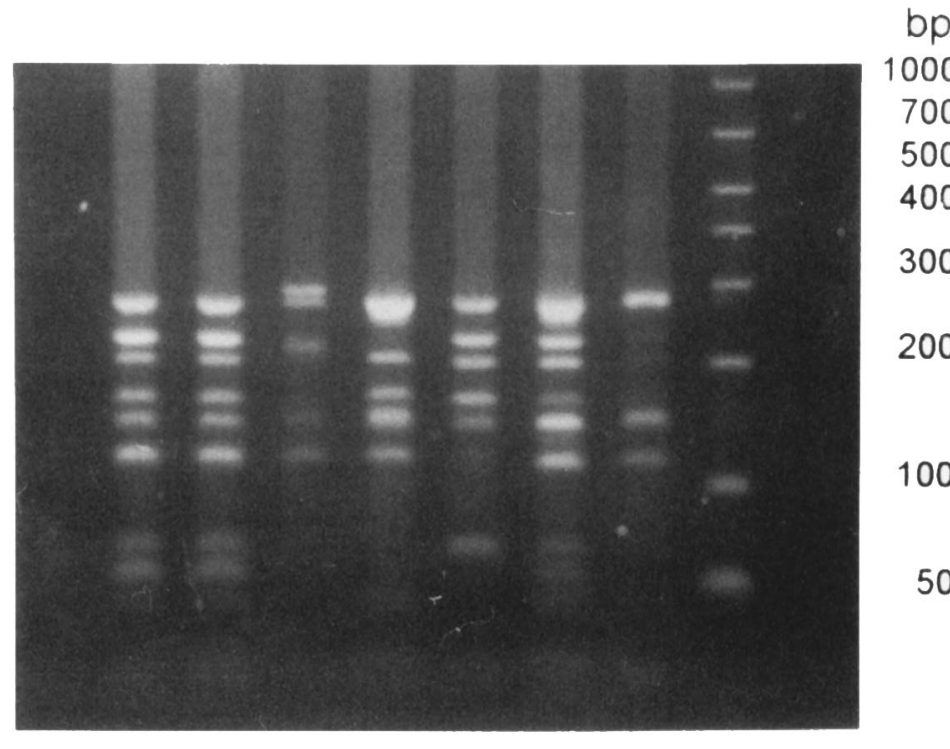

E1 E1' E2 N1 N2 N3 N4 M

Fig. 3. TaqI digests of the amplification products of the 16S-23S rRNA intergenic spacer region from the three environmental $B$. cepacia isolate types from hospital clinics (E1, El' and E2) and four B. cepacia reference isolates (N1, NCTC 10734; N2, NCTC 10743; N3, NCTC 10744; N4, NCTC 10661). M, BioRad ampliSize DNA markers.

were extracted and the target region was amplified within hours of extraction. Generally, PCR amplification with DNA from certain types (P2, A2) gave little or no product $2448 \mathrm{~h}$ after extraction when stored at $4^{\circ} \mathrm{C}$. Various extraction methods were used, including the methods described by Kostman et al., ${ }^{9}$ without improving this apparent instability of the extract. However, other types (P4 and A3) could be stored at $4^{\circ} \mathrm{C}$ for up to 5 days with little effect on PCR amplification. Poor PCR amplification was found frequently from all strains when DNA was extracted from cultures older than $24 \mathrm{~h}$. The reasons for this "inactivation" of the DNA template are unclear but the effect may have implications in the proposed extension of the method to identify $B$. cepacia directly in sputum specimens with simultaneous typing by use of specific primers to the ribosomal RNA gene

\section{References}

1. Isles A, Maclusky I, Corey $\mathbf{M}$ et al. Pseudomonas cepacia infection in cystic fibrosis: an emerging problem. $J$ Pediatr $1984 ; 104,206-210$

2. Simmonds EJ, Conway SP, Ghoneim LB, Ross H, Littlewood JM. Pseudomonas cepacia: a new pathogen in patients with cystic fibrosis referred to a large centre in the United Kingdom. Arch Dis Child 1990; 65, 874-877.

3. Govan JRW, Brown PH, Maddison J et al. Evidence for transmission of Pseudomonas cepacia by social contact in cystic fibrosis. Lancet $1993 ; 342 ; 15-19$.

4. Smith DL, Gumery LB, Smith EG, Stableforth DE, Kaufmann ME. Pitt TL. Epidemic of Pseudomonas cepacia in an adult cystic fibrosis unit: evidence of person-to-person transmission. J Clin Microbiol 1993; 31: 3017-3022.

5. Govan JRW, Harris G. Typing of Pseudomonas cepacia by bacteriocin susceptibility and production. J Clin Microbiol $1985 ; 22: 490-494$ complex of B. cepacia.$^{12}$ A negative result from sputum could indicate the absence of $B$. cepacia or failure to amplify for reasons other than primer mismatch.

The present study showed that PCR ribotyping followed by TaqI digestion is simple to perform and provides rapid, reproducible results. In comparison with the other typing methods applied to $B$. cepacia isolates from the Welsh CF patients, the results from this technique were as discriminatory as those obtained by PFGE and more discriminatory than those from bacteriocin typing (table). Currently it is the method of choice in our study of the epidemiology of B. cepacia.

We thank Mrs C. Doherty and Professor J. R. W. Govan for supplying the "epidemic strain" of $B$. cepacia, and also Professor Govan for the bacteriocin typing and Dr T. L. Pitt for the pulsedfield gel electrophoresis typing of the Welsh B. cepacia isolates. This work was supported by a grant from the Welsh Scheme for the Development of Health and Social Security.
6. Rabkin CS, Jarvis WR, Anderson RL et al. Pseudomonas cepacia typing systems: collaborative study to assess their potential in epidemiologic investigations. Rev Infect Dis 1989; 11: 600-607.

7. LiPuma JJ, Mortensen JE, Dasen SE et al. Ribotype analysis of Pseudomonas cepacia from cystic fibrosis treatment centers. $J$ Pediatr 1988; 113 : 859-862.

8. Anderson DJ, Kuhns JS, Vasil ML, Gerding DN, Janoff EN. DNA fingerprinting by pulsed field gel electrophoresis and ribotyping to distinguish Pseudomonas cepacia isolates from a nosocomial outbreak. J Clin Microbiol 1991; 29: $648-649$.

9. Kostman JR, Edlind TD, LiPuma JJ, Stull TL. Molecular epidemiology of Pseudomonas cepacia determined by polymerase chain reaction ribotyping. $J$ Clin Microbiol 1992; 30: 2084-2087.

10. de Lamballerie X, Zandotti C, Vignoli C, Bollet C, de Micco P. A one-step microbial DNA extraction method using 
"Chelex 100" suitable for gene amplification. Res Microbiol 1992; 143: 785-790.

11. Boom R, Sol CJA, Salimans MMM, Jansen CL, Wertheim-van Dillen PME, van der Noordaa J. Rapid and simple method for purification of nucleic acids. J Clin Microbiol 1990; 28 : 495-503.
12. Dasen SE, LiPuma JJ, Kostman JR, Stull TL. Characterization of PCR-ribotying in Burkholderia (Pseudomonas) cepacia. $J$ Clin Microbiol 1994; 32: 2422-2424

13 Millar-Jones L, Paull A, Sauders Z, Goodchild MC. Transmission of Pseudomonas cepacia among cystic fibrosis patients. Lancet 1992; 340: 491 